\title{
Research on the task-based Chinese teaching based on a multidimensional perspective
}

\author{
Chen Xiang \\ (School of International Culture Change, Central University of Finance and Economics)
}

\begin{abstract}
China's social economic has maintained rapid growth all years since the reform and opening up. Moreover, China has kept growing influence in the process of world economic integration due to the show of stronger potential for economic development in coping with the financial crisis. Therefore, the Chinese has aroused more and more attention from the world and gradually become a popular language. The task-based language teaching mode, which is the most influential mode, has significantly changed the Chinese teaching mode in the nearly 10 years of Chinese teaching reform. This paper gives an introduction on the meaning and basic mode of the task-based teaching. To address the problems task-based Chinese language teaching, such as the reasonableness of teaching schedule, the ignorance of the former stage and the latter stage, and the difficulty in the evaluation of the task design, the task design of Chinese teaching for foreigners is taken for an example, and the teaching task design is determined based on a multidimensional perspective of the teachers, the students and the others. Taking the target of task-based teaching as the guiding, the teaching tasks are designed, and the basic principles of the Chinese teaching task design are collated and summarized, so as to provide more available and practical modes of Chinese teaching for the task-based teaching of Chinese as a foreign language, promote the Chinese teaching as a foreign language teaching in the world successfully, and enhance the promoter action of the verbal communication for economic integration.
\end{abstract}

Keywords-Chinese teaching; task design; task-based teaching

\section{INTRODUCTION}

Due to the impact of the financial crisis and the European debt crisis, the world economy has presented the trend of slow economic growth as a whole in recent decade. The development of the Europe and the United States tends to stagnate. On the contrary, the continued rapid growth of China's economic alleviates the to concerns of people on the retrograde global economy to some extent. China has surpassed Japan to become the world's second largest economic entity, and the strong spending power of the Chinese market has attracted global attention. With the promotion of China's comprehensive national strength and status in the world, Chinese is becoming a more and more popular language. At the present time, the number of persons who learn and use Chinese worldwide is very impressive, and maintains a higher growth rate in the last consecutive 10 years[1]. The findings on the number of speakers using first language worldwide taken from the Organization for Economic Cooperation and Development
(OECD) are shown in Figure 1.

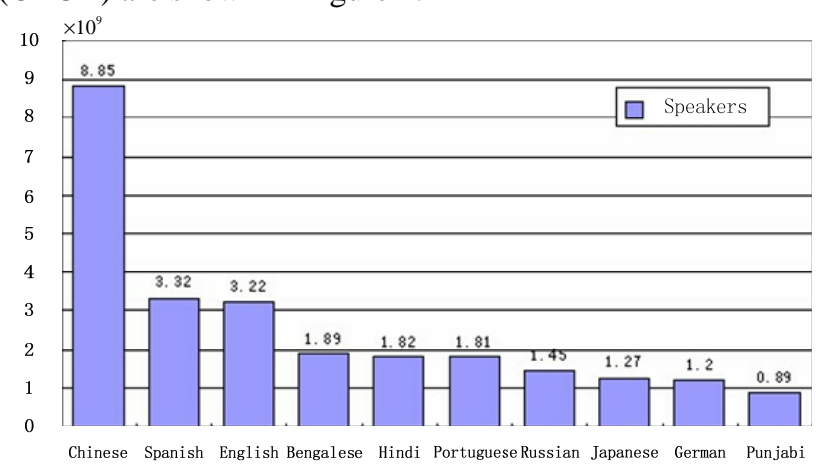

Fig. 1 The number of speakers using respective first language worldwide

Currently, there are more than 40 million people worldwide in an effort to learn the relative complex Chinese. Therefore, research on innovation of the teaching methods, teaching skills Chinese as well as teaching design of Chinese language and so on has become the new hot spot in the research of Chinese language teaching.

\section{TASK-BASED CHINESE TEACHING}

In the 1980s, Ellis, Willis and some other scholars proposed the task-based language teaching (Task-based Language Teaching) on the basis of the communicative approach[2,3]. The task-based teaching model promotes the "learning by doing", introduces the concept of the task into the language teaching process and carries out the language teaching according to the task. Through the effective combination of language learning and language application, the learners can learn the language and learn how to use the language to communicate with each other in the process of completing the task[4].

The task-based teaching model can promote the interaction between teachers and students, and has changed the past teaching mode of one-way transmission of information and improved the defect in traditional teaching model that is not conducive to the comprehensive language skills training[5]. During the task-based language teaching, not only that the teachers and students can have more opportunities for interaction, but also that the learners can build the mode of mutual help and support to learn language project in the process of completing the task together, so that they can concentrate more on learning language comprehension and language applications, and ultimately fulfill the object that they can describe the 
thoughts and ideas of their own completely and accurately.

In the 21st century, the number of education experts and scholars in China paying close attention to the task-based teaching continues to increase, and the research findings on the task-based teaching is gradually increasing. The mode of task-based teaching is changing the theory into practice. Although the task-based teaching mode of teaching abroad has practical experience for more than two decades, the time of applying the task-based teaching mode to Chinese language teaching is still very short. In addition, Chinese has several special characteristics such as the various voice, the lack of inflection as well as the rich semantics and other peculiarities, resulting in the high difficulty in task design for the task-based Chinese language teaching[6]. The current task-based teaching in China is mainly learned from foreign experience and used in English teaching of the primary and secondary schools.Therefore, to introduce the task-based teaching mode into the Chinese language teaching in China still need to face many problems to be solved.

\section{III.MAIN PROBLEMS IN TASK-BASED CHINESE TEACHING}

As an innovative teaching mode, the task-based Chinese teaching has several advantages such as strong interaction and so on. However, introducing the task-based teaching into our classrooms through the teaching reform really still faces many difficulties. The main problems are as follows:

First of all, the task-based Chinese language teaching takes a lot of class time. Before starting a task, language teachers need to give a simple introduction on the content and related basic vocabularies and phrases of the task to the learners. The teachers also need to give an overview of the cultural background so as to enhance the socio-linguistic environment in the process of the task. Therefore, the task-based teaching takes more classroom time., If a teaching task takes a lot of time, it means that this teaching is focused on long-term teaching effectiveness from the perspective of teaching arrangements. However, the Chinese language teaching task in China lacks the corresponding design experience, and there is no empirical data can be referred in the process of design tasks. The foreign education system and teaching evaluation are quite different from China, and the difficulty of education received by the students in the process of language learning is not high, so the education scholars of China have no mature instructional design cases to refer to. The lack of the design experience and teaching experience of the task-based teaching can easily lead to the uncontrolled difficulty in the process of task design, reducing the effect of Chinese teaching.

Secondly, the process to complete the task is given more attention, while ignoring the pre-task phase and post-task phase. It is generally believed by the language teachers and educational experts that the pre-task phase and post-task phase are optional in the process of current task-based language teaching. For example, Ellis, one of the proponents of the task-based teaching had made it clear that the activities of the task is a necessary stage, while the preparation phase of the task and the subsequent tasks analysis phase have little effect on teaching effectiveness[7]. Most scholars ignore the emotional communication from the opportunities of interaction between learners in the preparation phase of the task, and simply take the teaching task as a separate process of learning, bringing down the the advantages that the pre-task phase and post-task phase can enhance the socio-linguistic environment and that the language features of the learners can be re-emphasized in the process of repetitive tasks.

Finally, the language teachers lack the experience of task-based Chinese teaching, and it is extremely difficult to arrange the progress of teaching reasonably and evaluate the teaching effectiveness of improvisations. The Chinese language teaching in China is mainly divided into two categories: basic Chinese language teaching and foreigner-oriented Chinese language teaching. Due to the long-term implementation of the examination-oriented education, the evaluation system for teaching is single and the evaluation method is simple, so it is inevitable that applying the task-based teaching to the Chinese language teaching in the process of basic Chinese language teaching will encounter the problems of the evaluation of the effectiveness of teaching and evaluation methods. At the present time, there is no mature experience at home and abroad to be learned, so it is extremely difficult to evaluate the arrangement of teaching schedule and on-the-spot teaching effects. However, although the task-based teaching mode can guide students to a better understanding of Chinese culture and Chinese language culture in the process of foreigner-oriented Chinese teaching, the profound cultural heritage and socio-linguistic environment will increase the difficulty of the task design. Due to the changing context and the complex Chinese expression manners under different socio-linguistic environment may lead to the increase of difficulty in Chinese teaching task design. Therefore, plenty of practical experience is also required for the teachers to guid the aspects such as the completion of the task, the analysis of the task and others, so as to enrich the teaching forms.

Due to the special background of social development history, it is difficult to change China's basic chinese teaching situation in the short term. Therefore, Taking the foreigner-oriented Chinese teaching as the main object of study, this paper researches the mode and task design from the perspectives of task objectives, teacher-student role as well as teaching process and so on. 


\section{BASIC MODE AND TASK DESIGN OF TASK-BASED CHINESE TEACHING BASED ON A MULTIDIMENSIONAL PERSPECTIVE}

\section{A. Basic mode of Task-based Chinese teaching}

the basic mode of the task-based Chinese language teaching can be summed up as the pre-task phase, task phase and post-task phase according to the main features and advantages of the task-based teaching. The main content and objectives of the three phases of the task-based teaching are as follows:

The introduction of task topic and the completion of task preparation activities are done in the pre-task phase. Some recording or video similar and will not mislead the learners can be played to them when using the multimedia assisted teaching. The interest and enthusiasm of the learners are enhanced through the stimulation of sound and pictures, and some relevant information and cultural background materials are provided to the learners, so as to guide the learners to fulfill the task creatively and avoid simple repeating the completion process of example tasks. If the condition of the multimedia assisted teaching does not meet, some time can be given to students for planning the ways and steps to complete the task, so as to increase the interaction opportunities between learners, making them establish good communication mode with mutual communication, mutual help as well as mutual encouragement at the preparation phase.

The task stage is the core part of the task-based teaching mode. At this stage, the learners need to participate in small groups to complete the task together. Through the mutual help and mutual support, the interest and confidence of the learners can be enhanced. And through the exchange of information to complete the task, the understanding of the learners about the socio-linguistic environment of Chinese can also be intensified. In the process to complete the task, learners do not have to comply with strict discourse structure, and can transfer the right to speak according to the daily round rules. Through controlling the direction of the subject, learners can put question to some topics without given answers and carry out the discussion. Learners can not only react to the problems proposed by others, but also ask questions of their own, enhancing the effect of multidimensional language skills practice and strengthening the capabilities of learners on language comprehension, language expression and so on. When communication barrier appears in the process of competing the task, learners can resolve it by themselves through consultation, because there is no standard answers or standard processes. a variety of language features enhance the fun in language learning, learners can accept the content of language teaching more fully and forwardly in the completion of the task.

The task analysis and in-depth thinking are performed at the post-task, and further reflection can be expanded round the completion process and results of the group. The errors or inappropriate use of language of the learners can be corrected by the teachers at this stage, and learners can complete the task again after the task analysis in order to enhance the effect of learning. The basic mode of the task-based Chinese language teaching is shown in Figure 2.

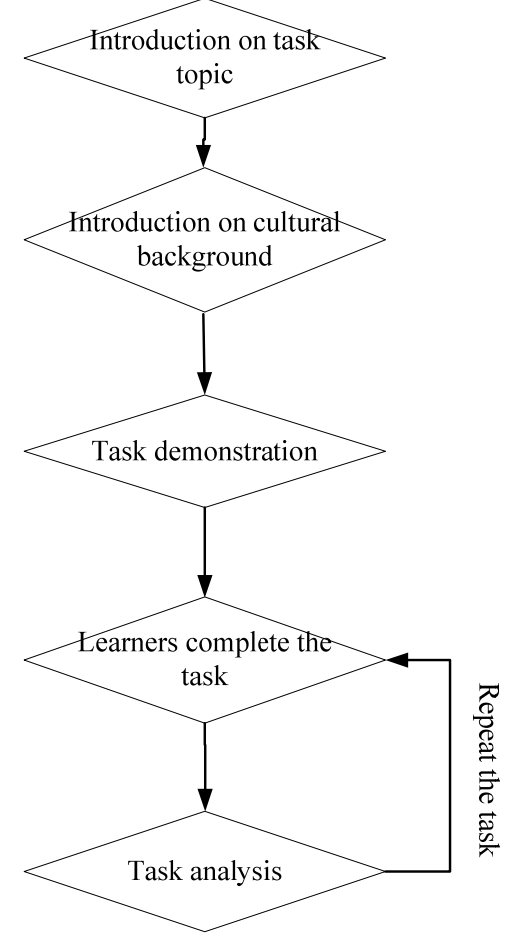

Fig. 2 The basic mode of task-based Chinese teaching

\section{B. Principles for task design}

A lot of principles for task design have already been proposed in the existing research of language teaching of China. Huang Danping believes that the tasks should be designed to follow the principles of student-centered[8]. Hu Xiaoai takes the principle of truthfulness as the principal principle for task design[9]. Chen Qiuming insists that the task should be designed to focus on the principles of diversity[10]. Considering the characteristics of task-based Chinese teaching and the existing experience of actual teaching, the task design of task-based Chinese language teaching should follow four principles, that is, interesting, practicability, applicability and hierarchy.

The interesting of the task directly affects the effect of the task, Tasks deviated from the real life will mislead the learners' understanding of Chinese culture, and can not mobilize the enthusiasm of the learners and achieve the objectives of the exchange of Chinese language. Therefore, the materials taken from living and learning, which the learners are interested in should be taken as the task topics in the process of the design of teaching tasks.

The ultimate goal of language teaching is to enable learners to communicate using language, so the principle of practicability is one of the main principles of task design. It is of great importance for the enhancement of teaching 
effectiveness that the language features excercised in tasks being applied in daily communication, such as the tasks of asking for directions, ordering and others can help learners to complete a simple verbal communication in daily life, and the continued practice in life will consolidate the effect of language teaching to a large extent.

The principle of applicability refers to that the difficulty of the task should be suitable for the teaching arrangements. tasks too long will affect the teaching schedule, and tasks too difficult will suppress the enthusiasm and confidence of learners. Therefore, the applicability of task should be tested repetitively in the process of task design.

The difference of students' language levels is the main reason why the task of teaching must have the principle of hierarchy. Simple tasks allow more learners to participate in, and the learning experience achieved is richer. With the accumulation of learning experience, the tasks are taken from easy ones to difficult ones, and from simple ones to difficult ones, so as to make more learners practice the language functions.

The process of task design should mainly comply with four principles of interesting, practicability, applicability and hierarchy. In addition, the principles of authenticity, diversity and so on should be taken into consideration.

\section{Task design of task-based Chinese teaching}

Task-based language teaching is the inheritance and development of the concept of the communicative teaching. The quality of the teaching task design will directly affect the success or failure of language teaching[11]. To address the problems in the design of Chinese teaching tasks such as the Chinese language teaching particular, the tasks lack practicability and is lack of interest and other issues, the foreigner-oriented Chinese teaching is taken as an example. From the roles of teachers and students and the perspective of learners, while taking the learner as the core, the task programs and materials are designed according to certain level. Simple tasks can be designed as follows:

Example 1: Let the learners introduce two memorable internship experience within five minutes.

After the subject of the task is given, the Chinese interns system and the differences of employment system of interns between China and USA should be introduced properly, and short time is given to learners to organize language and select the manner to complete the task. The level of difficulty can be improved after the learners have enhanced their language level, and the specific example is as follws:

Example 2: Discuss favorite movie or television series in group, and one of them is selected as the representative to give a brief summary of the discussion in the end of the discussion. The content of summary is ranged from 200 words to 250 words in length.

The role of teacher-student should be designed from a multidimensional perspective after the design of hierarchical task content. From the point of teachers and students, the teacher is no longer the proposer of problems and the organizer of activities, and should be converted to the designer, organizer, guide and evaluator of the task in the process of completing the task. The matters the teacher should do, the activities the teacher should take part in as well as the responsibilities the teacher should carry out and so on must be made definite at the stage of task design. The background information and related words are provided at the pre-task stage. At the task stage, the discussions are organized or the learners are guided to complete the task, and the language problems exposed from the students are taken down. Moreover, the task is analyzed, repeated and so on at the stage of post-task.

From the perspective of the learners, they are not only the participants of the task, but also the supervisors and innovators during the learning in the process of completing the task. Learners complete the adventure of the task and fulfill the multiple language features through mutual help, mutual support and mutual encouragement.

\section{CONCLUSION}

Through introducing the meaning and basic mode of the task-based teaching, and taking the task design of foreigner-oriented Chinese teaching as an example, the basic principles of the design of teaching tasks are determined based on a multidimensional perspective of teachers, students, learners and so on in this paper. The proposed principles can provide more comprehensive, feasible, practical and effective modes for Chinese teaching, so as to popularize the foreigner-oriented Chinese teaching in the world successfully and enhance the promoter action of the language communication on economic integration.

\section{REFERENCES}

[1]Zhang Fang. Research on the Task-Design of Task-Based Language Teaching[D]. Jilin University, 2012.

[2] Johnson K. Designing Language Teaching Tasks. 2003.

[3] Ellis R.Task-based Language Learning and Teaching. 2003 Ellis R.Task-based Language Learning and Teaching. 2003.

[4] Bachman LF, Palmer AS. Language Testing in Practice: Designing and Developing Useful Language Tests. 1996.

[5] Long M.H., J.M.Norris. Task-based language teaching and assessment. Encyclopedia of Language Teaching. 2000.

[6] Lin Lin. A Study on the Chinese Sicinized Task-based Language Teaching Mode[D]. Shandong Normal University. 2012.

[7] Skehan, P. Tasks and language performance assessment. Researching Pedagogic Tasks: Second Language Learning, Teaching and Testing. 2001.

[8] Huang Danping. Perspectives on the Task Design in Task-based Language Teaching[J]. Journal of Guangdong University of Technology(Social Sciences Edition), 2009, (06): 24-28.

[9] Hu Xiaoai. The construction and application research of the task design mode in language teaching[J]. China Electric Power Education, 2011, (20): 104-105, 115

[10] Chen Qiuming. Task Design in Task-based Chinese Speaking Class[D]. East China Normal University, 2011.

[11] Nie Ying. Exploration and Practice on Task-based Spoken Chinese Teaching of Teaching Chinese as Foreign Language(TCFL)[D]. Zhejiang University, 2012. 